\title{
Oxygen saturation changes in relation to the use of gloves: an uncontrolled before and after intervention study
}

Rocío Nieto Pérez

Madrid Health Service

María Martínez Gascón

Hospital Universitario 12 De Octubre

Marina Guisado-Clavero ( $\square$ marina.guisado@salud.madrid.org )

Madrid Health Service

Sara Ares-Blanco

Madrid Health Service

Research Article

Keywords: COVID-19, gloves, pulse oximetry, oxygen saturation.

Posted Date: March 12th, 2021

DOI: https://doi.org/10.21203/rs.3.rs-275983/v1

License: @ (i) This work is licensed under a Creative Commons Attribution 4.0 International License.

Read Full License 


\section{Abstract}

Background: Nurses have had an essential role in health promotion (hand washing, social distance and wearing a mask) during COVID-19 pandemic. However, some patients wear gloves, which is a possible barrier to proper examination. The aim of this study was to determine the difference in oxygen saturation measurement with or without the use of powder-free nitrile gloves.

Methods: A prospective quasi-experimental before and after study was conducted in a primary care practice (PCP) from Madrid. Intervention consisted in measuring oxygen saturation (SpO2) for each participant covering a finger with a powder-free nitrile glove and a posterior measure without glove. Data collection was obtained from June to July 2020 with patients of the PCP. Variables included were demographic data (age and sex), respiratory medical history and suspicion of COVID-19. Descriptive statistics were expressed as frequencies or means with its standard deviation (SD). Effect of gloves was obtained performing Student's t-test and agreement was determined by Bland-Altman analysis. Data was stratified by age range.

Results: 177 patients participated in the intervention, mean age was 58.7 (SD: 18.8) years and $53.7 \%$ were female, $19.8 \%$ had smoke habit, $18.1 \%$ had respiratory medical history and $27.7 \%$ were suspicious COVID-19 case. No differences were observed in SpO2 intervention across age groups ( $p$ value 0.058 with gloves and 0.150 without). There were statistical significance difference in: patients $<50$ years (SpO2: $+0.65)$, 50-75 years (Sp02: +0.62), females (Sp02: +0.79), smokers (SpO2: +0.60) and COVID suspicious cases (Sp02: +0.64). Bland-Altman analysis was performed, mean difference was $-0.56 \pm 1.38 \%(95 \% \mathrm{Cl}$, -0.77 to -0.35$)$, and the limits of agreement were -3.32 and $2.19 \%$.

Conclusions: The use of powder-free nitrile glove do not change SpO2 with pulse oximetry in general population. However, those patients with potential lung affection might have measures without gloves. Nursing is crucial to educate and prevent from COVID-19 infection.

\section{Background}

The World Health Organization (WHO) declared New Coronavirus 2019/2020 (COVID-19) a pandemic on March 11, 2020 (1). As of January 23, 2021, 95,612,831 cases of COVID-19 have been registered worldwide, with 2,499,560 confirmed by reverse transcription polymerase chain reaction (RT-PCR) in Spain (2). A total of 578,371 positive cases have been registered in Madrid (3).

The SARS-CoV-2 transmission mechanism is still being described, and current studies suggest that close contact of infected respiratory secretions to oral, nasal or conjunctival mucosa, either directly or indirectly, could transmit it (4). Additionally, airborne transmission has been recognized (5). The WHO has implemented physical distancing, facial masks and hand hygiene as tools to avoid SARS-CoV-2 infection. These recommendations have been followed widely by the global population. In addition, other protective behaviours, such as wearing face shields or gloves in public, have been frequently implemented, although 
neither the WHO nor the Center for Disease Control and Prevention (CDC) recommend these measures $(6-7)$.

The classical triad of COVID-19 symptoms includes fever, dyspnoea and cough, and pneumonia has been described as one of the primary complications. Physical examination can help to determine COVID-19 progression, which can be mild or severe, depending on respiratory effects and oxygen saturation (SpO2). Peripheral capillary SpO2 can be measured by pulse oximetry. The device works through a red-light beam that is sent to the finger and measures the light wavelengths absorbed by oxygenated haemoglobin. Normal SpO2 values range between $95 \%$ and $100 \%$ with a deviation of $2 \%$. Values below $95 \%$ at rest can be associated with several acute and chronic diseases (8). The severity of SARS-CoV-2 infection can be monitored by pulse oximetry, and values lower than $94 \%$ are correlated with more serious infection (9).

During the COVID-19 pandemic, the organization of primary care practices has changed drastically. Patients whose doubts could be resolved by remote assessment did not come to the practice. Those with mild and uncomplicated symptoms of COVID-19 came to the practice for RT-PCR and examination if needed. Many patients who came to primary care practices wore their own gloves as they feared becoming infected. At the beginning of these visits, each patient was evaluated by nurses to assess whether COVID-19 symptoms were present. Temperature was collected in all cases as well as SpO2 if they had respiratory symptoms. In some cases, gloves were not removed and SpO2 measure did not seem to differ from those occasions where patients did not have gloves. However, there was no evidence to support this practice. Therefore, the aim of this study was to evaluate differences in SpO2 measurements with or without gloves using pulse oximetry in the general population across different ages and in patients with respiratory diseases.

\section{Methods}

\section{Study design and sample}

This was a prospective quasi-experimental before and after study. Data were collected, and intervention was performed from June 9, 2020 to July 7, 2020 in a primary care practice (PCP) in Madrid, Spain (Federica Montseny PCP). Thirteen nurses and fourteen general physicians (GPs) worked in this centre, and they provided medical care to 21,814 patients.

Participants: Patients who were assessed at triage or at nursing consultation for any reason were invited to participate. The inclusion criteria were as follows: patients over 18 years old who sought medical advice (if patients were between 14 and 17 years, their legal guardian could provide permission for them to participate) and patients who gave their informed consent after oral information about the study. Exclusion criteria included patients with hand deformities, terminally ill patients, patients who had tremors or severe anaemia because it could interfere with the measurements and patients with nail polish or dirty nails.

\section{Sample size}


To calculate the sample size for the comparison of two paired means of data, a type I error of 0.5 , a test power of 0.8, and a clinical effect magnitude (difference in SpO2 before and after taking the gloved value) of 2 were established with a correlation of 0.5 and a standard deviation of 6 . Using Stata version 16 , a minimum sample size of 73 individuals was obtained.

Intervention: Study consisted in measuring SpO2 for each participant covering a finger with a powder-free nitrile glove and a posterior measure without glove.

First, informed consent was requested, and if the patients agreed, they were asked to participate in the study.

The following data were collected during the visit: age, sex (male or female), smoking habit (yes or no), respiratory chronic disease (asthma or COPD) and suspicion of COVID-19 (yes or no). Next, hydroalcoholic gel was offered for hand hygiene, pulse oximetry was always assessed in the fourth finger of the right or left hand, and data were collected. Second, patients were provided with fingerstall powderfree nitrile examination gloves of the appropriate size, and SpO2 measurement was repeated and recorded (Fig. 1). In those cases where patients had oxygen saturation below 95\%, we established a protocol (Supplementary file 1).

The pulse oximeter used was GIMA, model OXY-6. The gloves were powder-free nitrile examination gloves of the Sensiflex Lite brand in three sizes, S, M and L.

\section{Variables and data collection}

The information recorded included demographic data (age and sex), respiratory medical history (smoking habit and respiratory diseases) and suspicion of COVID-19. Variables were classified as follows.

- Qualitative variables: sex (male or female), smoking habit (dichotomous), respiratory chronic disease (asthma or Chronic Obstructive Pulmonary Disease (COPD)) and suspicion of COVID-19 (dichotomous).

- Quantitative variables: age, SpO2 measures before and after the intervention (represented as percentage and taken on air).

Data analysis: Descriptive statistics were performed. Qualitative variables are expressed as frequencies (standard deviation (SD)), and quantitative variables are expressed as the mean (SD). The effect of the use of gloves or not was determined by comparing both measurements. For this purpose, Student's t-test was performed for the data: quantitative variables of dependent samples with values before and after an intervention (use of nitrile gloves). Bland-Altman analysis was used to determine the agreement between $\mathrm{SpO} 2$ with gloves and without gloves. The data were analysed separately in three age ranges: $<50$ years, $50-75$ years and $\geq 75$ years.

\section{Results}


Descriptive data are represented in Table 1. A total of 177 patients were enrolled, the mean age was 58.7 (SD: 18.8 ) years, and $53.7 \%$ were female. Smoking habit was present in $19.8 \%$ of the sample, more frequent in those $<50$ years $(33.0 \%, p<0.001)$. The $18.1 \%$ had respiratory medical history, asthma was $11.3 \%$ and chronic obstructive pulmonary disease was present in $6.8 \%$ but no statistical difference was found across age groups. Suspicious COVID-19 infection was detected in $27.7 \%$ of the sample, being more frequent in those $<50$ years $(40.0 \%, p<0.028)$.

Table 1

Patients demographics and comorbidities characteristics stratified by age groups.

\begin{tabular}{|c|c|c|c|c|c|}
\hline & All & $<50$ years & $50-75$ years & $\geq 75$ years & $p$ value \\
\hline Total number, $\mathrm{n}(\%)$ & $177(100)$ & $57(32.2)$ & $76(42.9)$ & $44(24.9)$ & \\
\hline Age, mean (SD) & $58.7(18.8)$ & $36.5(9.3)$ & $62.0(7.1)$ & $81.9(4.9)$ & $<0.001$ \\
\hline \multicolumn{6}{|l|}{ Sex, n (\%) } \\
\hline Female & $95(53.7)$ & $30(53.0)$ & $43(57.0)$ & $22(50.0)$ & 0.77 \\
\hline Male & $82(46.3)$ & $27(47.0)$ & $33(43.0)$ & $22(50.0)$ & \\
\hline \multicolumn{6}{|l|}{ Respiratory medical history } \\
\hline Smoke habit, n (\%) & $35(19.8)$ & $19(33.0)$ & $14(18.0)$ & $2(5.0)$ & 0.001 \\
\hline Asthma, n (\%) & $20(11.3)$ & $9(16.0)$ & $6(8.0)$ & $5(11.0)$ & 0.097 \\
\hline COPD, n (\%) & $12(6.8)$ & $0(0.0)$ & $7(9.0)$ & $5(11.0)$ & 0.097 \\
\hline Suspicious COVID-19 case, $n$ (\%) & $49(27.7)$ & $23(40.0)$ & $18(24.0)$ & $8(18.0)$ & 0.028 \\
\hline
\end{tabular}

Differences in SpO2 measures using gloves are shown in Table 2. Using powder-free nitrile gloves overestimate $\mathrm{SpO} 2$ in all variables analysed but it was an increase of less than $1 \%$. We observed significant differences in SpO2 values in patients $<50$ and $50-75$ years, from $97.61 \%$ with gloves and $96.85 \%$ compared to $96.96 \%$ and $96.23 \%$ respectively ( $p$ value 0.001 and 0.002 ). In addition, our findings revealed differences in females with gloves (Sp02 97.32\%) and without gloves (SpO2 96.53\%, $p$ value 0.001 ) and in smoking habits (SpO2 of $96.97 \%$ with gloves and SpO2 96.37\% without, $p$ value 0.003 ). And no statistical differences were detected in patients who had respiratory diseases. When a BlandAltman analysis was performed to assess the agreement between the results of $\mathrm{SpO} 2$ without gloves and Sp02 with gloves, the mean difference was $-0.56 \pm 1.38 \%(95 \% \mathrm{Cl},-0.77$ to -0.35$)$, and the limits of agreement were -3.32 and $2.19 \%$ (Fig. 2). 
Table 2

Differences between Sp02 measured with and without gloves.

\begin{tabular}{|lllll|}
\hline & $\begin{array}{l}\text { SpO2 with } \\
\text { gloves (\%) }\end{array}$ & $\begin{array}{l}\text { SpO2 without } \\
\text { gloves (\%) }\end{array}$ & $\begin{array}{l}\text { Difference (\%) (SpO with - } \\
\text { SpO2 without gloves) }\end{array}$ & $\begin{array}{c}\text { Student's T } \\
\text { test ( } \boldsymbol{p} \text { value) }\end{array}$ \\
\hline Age group & & & & \\
\hline Patients $<50$ & 97.61 & 96.96 & 0.65 & 0.001 \\
\hline Patients $50-74$ & 96.85 & 96.23 & 0.62 & 0.002 \\
\hline Patients $\geq 75$ & 96.43 & 96.06 & 0.37 & 0.197 \\
\hline Sex & & & & 0.79 \\
\hline Female & 97.32 & 96.53 & 0.30 & 0.091 \\
\hline Male & 96.60 & 96.30 & 0.64 & 0.001 \\
\hline $\begin{array}{l}\text { Respiratory } \\
\text { medical history }\end{array}$ & 97.00 & 96.36 & 0.60 & 0.003 \\
\hline Smokers & 96.97 & 96.37 & 0.17 & 0.811 \\
\hline COPD & 95.00 & 94.83 & 0.45 & 0.329 \\
\hline Asthma & 96.80 & 96.35 & 0.64 & 0.001 \\
\hline $\begin{array}{l}\text { Suspicious of } \\
\text { COVID-19 case }\end{array}$ & 97.00 & 96.36 & & \\
\hline Legend: SpO2 (oxygen saturation); COPD (chronic obstructive pulmonary disease) & \\
\hline
\end{tabular}

\section{Discussion}

Up to 177 patients participated in the intervention with a mean age of 58.7 (SD: 18.8) years and $53.7 \%$ were female. There were differences between the use and absence of powder-free nitrile examination gloves when measuring Sp02. The use of gloves overestimates by less than $1 \%$ the measure of SpO2 in patients and was statistical significant in female patients, $<75$ years, smokers and those with suspicion of COVID-19.

Oximetry is a common technique in different nursing settings and there are some studies that describe the influence of oximetry when any surface (nail polish, gloves, dirt, etc.) is on the nail or the finger. We should keep in mind that SpO2 varies from different oximetry brands (10-11). Bickler et al. studied the differences between SpO2 and haemoglobin oxygen saturation. SpO2 was measured by oximetry, and haemoglobin oxygen was measured by a haemoximeter blood gas analyser. They described the mean bias (the difference between SpO2 and haemoglobin oxygen saturation) among different oximetry brands according to the pigments on the skin (dark, intermediate and light) (10). They found that SpO2 
was overestimated between $2-3 \%$ in dark subjects when the SpO2 was $60-70 \%$; however, these differences disappeared when Sp02 was between 90-100\%. Adler et al. found no differences among pigments on the skin when they compared oximetry and arterial blood sampling in the Accident \& Emergency (A\&E) department (12). But Sjoding et al. described recently that Black patients had almost three times the frequency of occult hypoxemia than White patients when using pulse oximetry compared with arterial blood gas test (13). Then, racial bias according to differences in skin pigment should be considered when measuring $\mathrm{SpO} 2$ with pulse oximetry.

Focusing on the surface of the skin, some studies have been performed primarily in women by studying henna tattoos influence in Sp02. Mitra Zolfaghari et al. found no significant differences between measurements in 100 young women (SpO2 in henna finger: 95.32\% vs SpO2 in control finger: 95.29\%, $p$ value 0.87) (14). Sütçü Çiçek et at. compared the SpO2 of normal fingers to henna tattoos and 13 different colours of nail polish in 33 healthy women (15). They found similar results in henna tattoos, but nails that were polished had higher Sp02 (polished nail: $98.00 \%$ vs control finger; $97.87 \%$ ). Our findings support their results because glove caused an increase of SpO2. However, an overestimation of less than $1 \%$ is not considered clinically relevant. On the other hand, considering nail surface, the effect of nail polish in the SpO2 measure is controversial. In 1986, Kataria published that nail polish did not interfere with oximetry, but she did not examine the colour of the nail polish (16). While other studies conclude that blue, green, black, brown and red colours interfere in SpO2 obtained with pulse oximetry with a difference of less than 1-2\% (17-19). A further aspect that must be addressed is the corporal temperature. Ralston et al. concluded that there are differences in pulse oximetry and in vitro oximetry saturation if the corporal temperature varies; they had as reference a central temperature of $37^{\circ} \mathrm{C}$ and found that while SpO2 could vary in hyperthermia or hypothermia, these differences were not clinically relevant (20). This situation is not a key aspect in COVID-19 disease, as fever is defined as a peripheral temperature over $37.3^{\circ} \mathrm{C}$ (4) so $\mathrm{SpO} 2$ measure could be modified by hyperthermia of $37.5^{\circ} \mathrm{C}$. Additionally, it should be taken into account that age can modify Sp02, and patients $\geq 75$ years had the lowest SpO2 (96.06\%). This finding is similar to a population of nursing home patients who had a basal value of $96.40 \%$ (22). Lung loss of elasticity could be the cause of older people having a lower Sp02 value. Finally, our study is similar to Burge et al. Both studies were conducted because of the challenges that nurses faced in clinical scenarios. They found that there were no differences in the measures of Sp02 with or without gloves; however, their study did not detail the type of gloves or the oximetry brand used. Our findings are consistent with their results, furthermore our sample is larger ( $n: 177)$ than theirs ( $n$ : 50) (21).

According to our study, the use of gloves overestimates oximetry by nearly $1 \%$ and this difference is not clinically relevant. Then it could be accepted to determine $\mathrm{SpO} 2$ in those population who are using gloves. However, neither the WHO nor the CDC recommends the use of gloves to prevent COVID-19. The data obtained in this study are useful in primary care, such as in the A\&E department, so no generalisation of using glove should be stablished in general population. Then, nurses are crucial for promoting health and preventing disease through health education. This task has been recognized by the WHO and is essential during the COVID-19 pandemic (23). Nurses have expanded their competencies during COVID-19 by caring for patients with mild symptoms, collecting RT-PCR, and recommending 
isolation and hygienic measures. They have increased their roles as they are in charge of triage not only in the A\&E department but also in primary care practices.

\section{Strengths And Limitations}

Our study has the strength of collecting a large sample of patients; furthermore, we studied respiratory patients, suspicious COVID-19 patients and smokers. We only used one type of glove and a single pulse oximeter model, so our results can be reproduced under the same conditions in different settings.

Some limitations should be considered. First, participants were only recruited from a single practice. Second, we did not collect the colour of the skin of our patients or their temperature, which could modify $\mathrm{SpO} 2$ values. Additional studies are needed to explain how different gloves (materials, colours, etc.) may interfere in SpO2 measurements.

\section{Conclusions}

Using powder-free nitrile gloves overestimate Sp02 measure less than 1\%. Differences observed where not clinically relevant. We recommend not to use gloves in those patients with lung affection or COVID-19 suspicious cases. Nurses have an essential role in health education and prevention in COVID-19 pandemic.

\section{List Of Abbreviations}

New Coronavirus 2019/2020: COVID-19

World Health Organization: WHO

Transcription polymerase chain reaction: RT-PCR

Primary care practice: PCP

Oxygen saturation: SatO2

Centers for Disease Control and Prevention: CDC

General Physicians: GPs

Chronic Obstructive Pulmonary Disease: COPD

Standard deviation: SD

\section{Declarations}


Ethical approval and consent to participate: The protocol of the study was approved by the Committee on the Ethics of Clinical Research of the Hospital 12 de Octubre on June 9, 2020 (Protocol No: P20/282).

The study was performed in accordance with the ethical standards of the Declaration of Helsinki (1964) and its subsequent amendments. Data were processed in accordance with Organic Law 3/2018 of December 5, Protection of Personal Data and Guarantee of Digital Rights. All participants provided informed consent. Guideline considered corresponded to nursing specific assessment (8).

\section{Consent for publication: Not applicable}

Availability of data and materials: The datasets generated and/or analysed during the current study are not publicly available due to the need to maintain the anonymity of participants but are available from the corresponding author on reasonable request and with permission of the Madrid healthcare system.

Conflict of interests: The authors declare they have no competing interests.

Funding: This manuscript has received a grant from the Foundation for Biomedical Research and Innovation in Primary Care (FIIBAP) for translation and publication in 2020 (FIIBAP/oct20).

Authors' contributions: Study concept and design: MMG, RNP, MGC, and SAB. Analysis and interpretation of data: SAB, MGC, MMG, and RNP. Drafting of the manuscript: MMG, RNP, SAB, and MGC. RNP and MGC prepared tables and figures. All authors have read and approved the finalized manuscript.

Acknowledgements: We would like to thank all the healthcare professionals who work at the Federica Montseny PCP. The nurses who collaborated in recruiting patients were María Tamara Zarco Duque; Ana Yarritu Sánchez; Fabia Sara Sananes Venero; María Isabel Vaquero Fuente; Raquel Blanco Corral; María de las Mercedes Zumel Álvarez; Álvaro Orihuel Pérez-Klett; and María Pilar Jareño Montserrat. This work could not have been done without their effort and dedication. We would like to thank Cristina Lozano Hernández and Miguel Menéndez for guidance in the revision of the manuscript.

\section{References}

1. World Health Organization. [Internet]. WHO Director-General's opening remarks at the media briefing on COVID-19 - 11 March 2020. Ginebra; 11th March, 2020. Available from: https://www.who.int/es/dg/speeches/detail/who-director-general-s-opening-remarks-at-the-mediabriefing-on-covid-19--11-march-2020 [Accessed 23th January, 2021].

2. Ministerio de Sanidad, Consumo y bienestar social. [Internet]. Información por nuevo coronavirus, COVID-19. Situación actual Madrid: Ministerio de Sanidad, Consumo y bienestar social. Available from: https://www.mscbs.gob.es/profesionales/saludPublica/ccayes/alertasActual/nCovChina/situacionActual.htm [Accessed 23th January, 2021].

3. Comunidad de Madrid [Internet]. Madrid: 2021. 2019-Nuevo Coronavirus. Available from: https://www.comunidad.madrid/servicios/salud/2019-nuevo-coronavirus [Accessed 23th January, 2021]. 
4. Zou L, Ruan F, Huang M, Liang L, Huang H, Hong Z, et al. SARS-CoV-2 Viral Load in Upper Respiratory Specimens of Infected Patients. N Engl J Med. 2020; 382(12): 1177-1179.

5. World Health Organization. [Internet]. Transmission of SARS-CoV-2: implications for infection prevention precautions. Ginebra: World Health Organization; 9 July 2020. Available from: https://www.who.int/news-room/commentaries/detail/transmission-of-sars-cov-2-implications-forinfection-prevention-precautions [Accessed 5th August 2020].

6. World Health Organization. [Internet]. Ginebra: Coronavirus disease (COVID-19) advice for the public. Available from: https://www.who.int/es/emergencies/diseases/novel-coronavirus-2019/advice-forpublic [Accessed 5 August 2020].

7. Center for desease control and prevention. [Internet]. Cómo protegerse y proteger a los demás. Available from: https://www.cdc.gov/coronavirus/2019-ncov/index.html [Accessed 10 August 2020]

8. Arribas Cachá A et al. Valoración enfermera. Herramientas y técnicas sanitarias. $3^{\circ} \mathrm{ed}$. Madrid: FUDEN; 2015.

9. World Health Organization [Internet]. Clinical management of severe acute respiratory infection when novel coronavirus ( $\mathrm{nCoV}$ ) infection is suspected. Available from: https://www.who.int/publicationsdetail/clinical-management-of-severe-acute-respiratory-infection-when-novel-coronavirus-(ncov)infection-is-suspected. [Accessed: 1th March 2020].

10. Bickler PE, Feiner JR, Severinghaus JW. Effects of skin pigmentation on pulse oximeter accuracy at low saturation. Anesthesiology. 2005;102(4):715-9.

11. Feiner JR, Severinghaus JW, Bickler PE. Dark skin decreases the accuracy of pulse oximeters at low oxygen saturation: The effects of oximeter probe type and gender. Anesth Analg. 2007;105.

12. Adler JN, Hughes LA, Vtvilecchia R, Jr. CAC. Effect of Skin Pigmentation on Pulse Oximetry Accuracy in the Emergency Department. Acad Emerg Med. 1998; 5(10):965-70.

13. Sjoding MW, Dickson RP, Iwashyna TJ, Gay SE, Valley TS. Racial bias in pulse oximetry measurement. NEJM. 2020; 383(25): 2477-2478.

14. Zolfaghari M, Majd PM, Aeen FB, Mohseni AR, Ahangari KA, Haghani H. Does henna impact pulse oximetry results? Emerg Med J. 2015; 32(3): 248-9.

15. Çiçek HS, Gümüs S, Deniz Ö, Yildiz Ş, Açikel CH, Çakir E, et al. Effect of nail polish and henna on oxygen saturation determined by pulse oximetry in healthy young adult females. Emerg Med J. 2011; 28(9): 783-5.

16. Kataria BK, Lampkins R. Nail polish does not affect pulse oximeter saturation. Anesth Analg. 1986; 65(7): 824.

17. Coté CJ, Goldstein EA, Fuchsman WH, Hoaglin DC. The effect of nail polish on pulse oximetry. Anesth Analg. 1988; 67(7): 683-6.

18. Hakverdioğlu Yönt G, Akin Korhan E, Dizer B. The effect of nail polish on pulse oximetry readings. Intensive Crit Care Nurs. 2014; 30(2): 111-5. 
19. Desalu I, Diakparomre OI, Salami AO, Abiola AO. The effect of nail polish and acrylic nails on pulse oximetry reading using the Lifebox oximeter in Nigeria. Niger Postgrad Med J. 2013; 20(4): 331-335.

20. Ralston AC, Webb RK, Runciman WB. Potential errors in pulse oximetry. Anaesthesia. 1991; 46(3): 202-206.

21. Burge A, Green M, Russell-Jones D. Patient power-Kidd Gloves. Clinical Medicine. 2018; 18(5): 437.

22. Sarabia Cobo CM, Diez Saiz Z, San Millán Sierra S, Salado Morales L, Clemente Campo V. Saturación de oxígeno en mayores institucionalizados: estudio comparativo. Gerokomos, 2015; (26). p. 53-55

23. World Health Organization. [Internet]. Educación para la salud: Manual sobre educación sanitaria en atención primaria de salud. Available from: https://apps.who.int/iris/handle/10665/38660. [Accessed 23th September 2020].

\section{Figures}

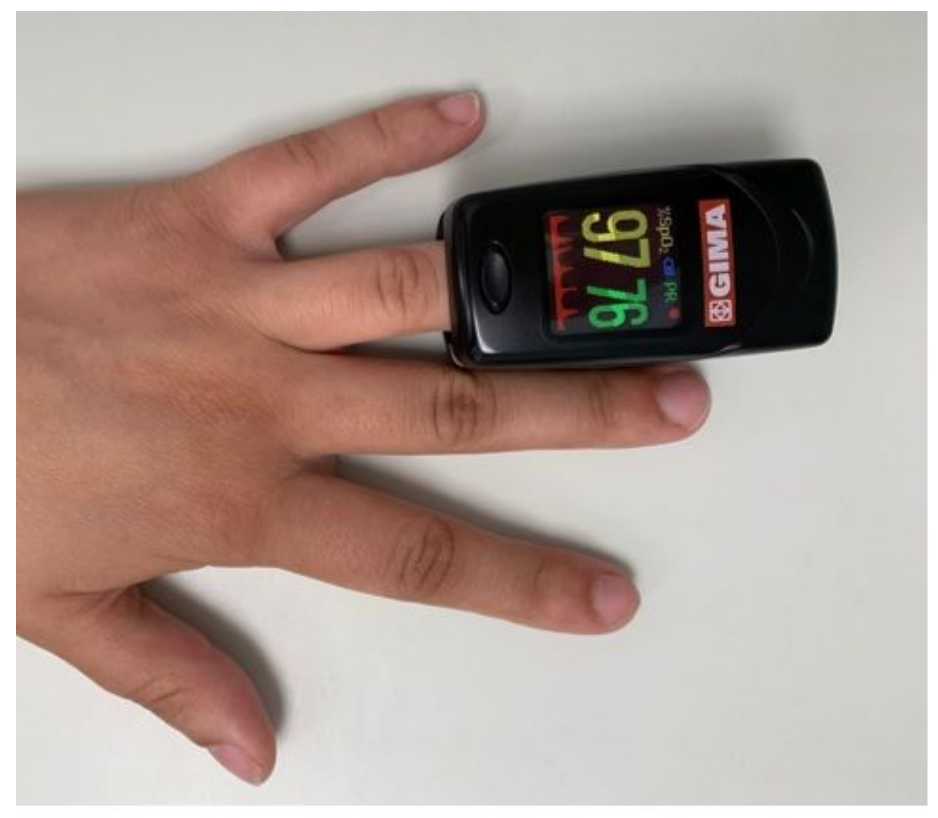

Figure 1.A

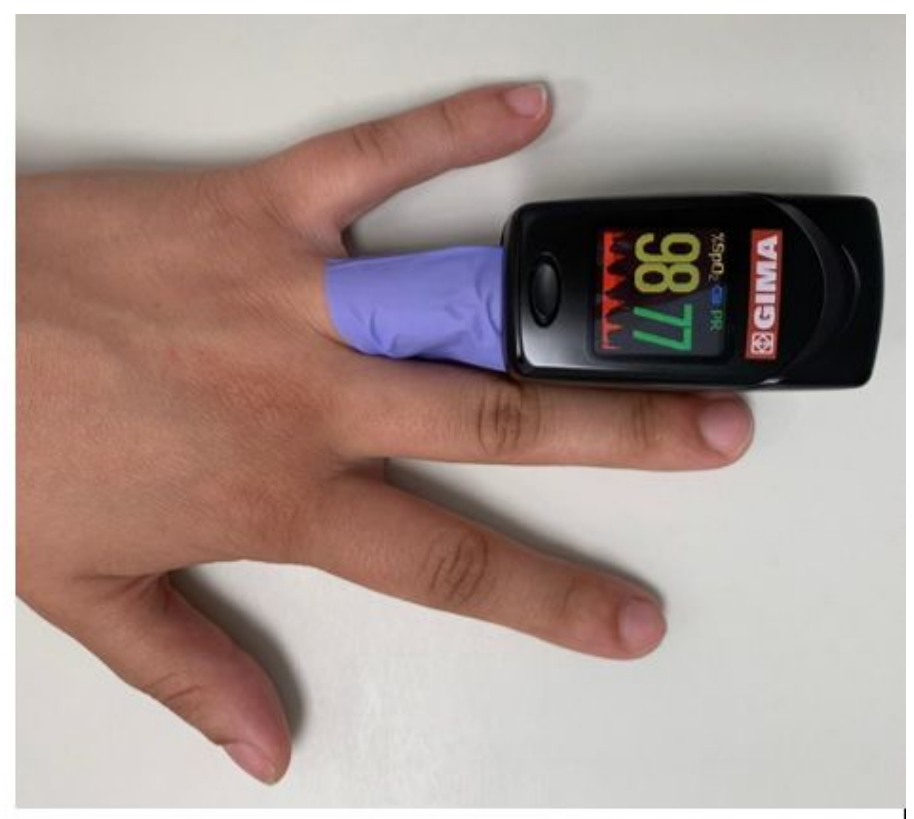

Figure 1.B

\section{Figure 1}

Peripheral capillary oxygen saturation measured with pulse oximetry. A. Measured without gloves. B. Measured with gloves. 


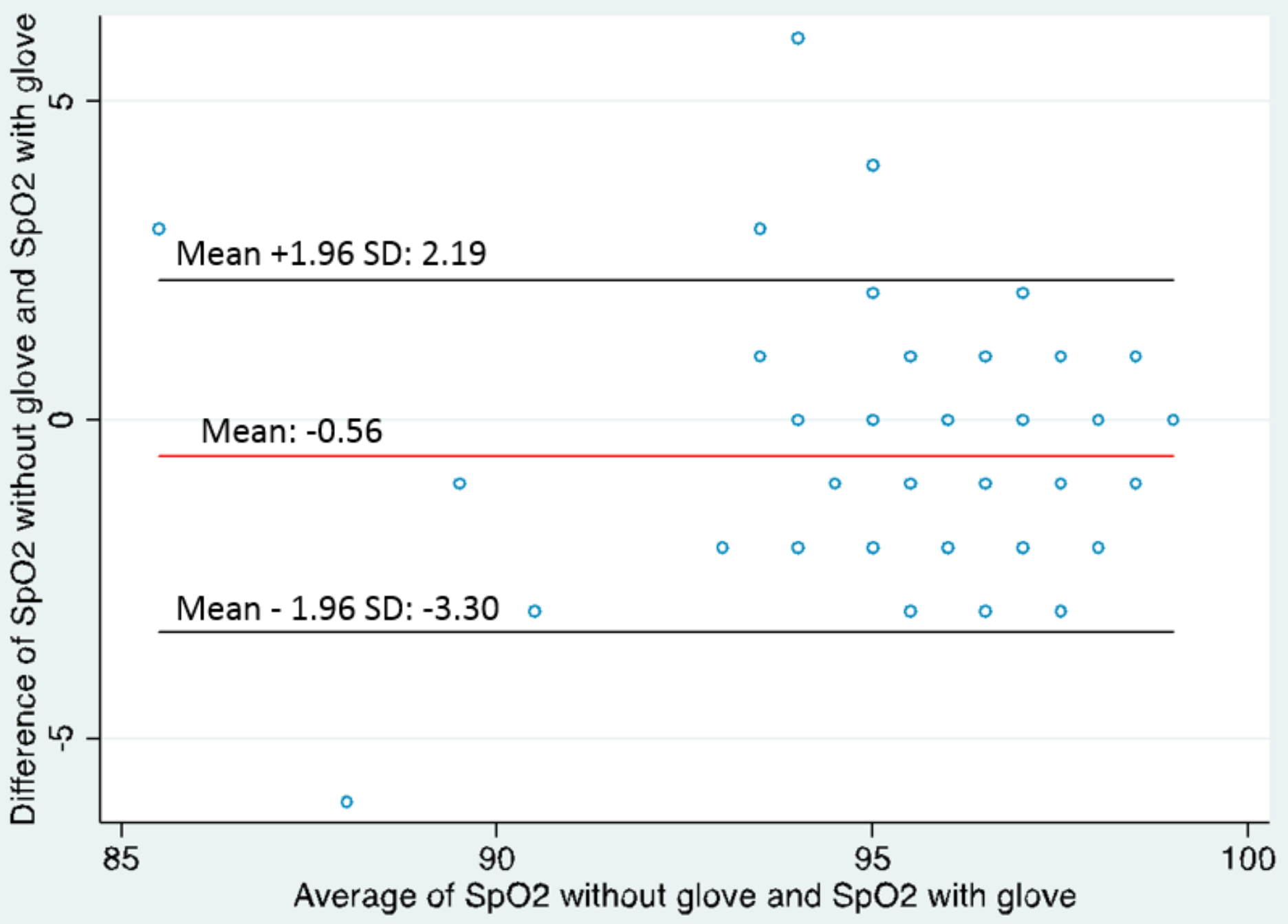

Figure 2

Bland and Altman plot of the difference between SpO2 with and without gloves against the mean of the $\mathrm{SpO} 2$ with and without glove of the study population. SpO2 (oxygen saturation), SD (standard deviation)

\section{Supplementary Files}

This is a list of supplementary files associated with this preprint. Click to download.

- Supplementaryfile1.jpg 